\title{
REVIEW
}

\section{Swallowing evaluation with videofluoroscopy in the paediatric population}

\author{
Valutazione della funzione deglutitoria in videofluoroscopia nei pazienti pediatrici \\ G. LO RE, F. VERNUCCIO, M.L. DI VITTORIO, L. SCOPELLITI, A. DI PIAZZA, M.C. TERRANOVA, D. PICONE, \\ C. TUDISCA, S. SALERNO \\ Section of Radiology Di.Bi.Med., University Hospital "Paolo Giaccone", Palermo, Italy
}

\section{SUMMARY}

Paediatric swallowing disorders can have several causes, from prematurity and congenital anomalies to gastro-oesophageal reflux and infective or inflammatory pathologies of the upper digestive tract. In neonates, the swallowing process is reflexive and involuntary. Later in infancy, the oral phase comes under voluntary control, while the pharyngeal phase and oesophageal phases remain involuntary. Swallowing difficulties can severely compromise pulmonary health and nutritional intake of paediatric patients. Videofluoroscopic Swallow Study (VFSS) is a radiographic procedure that provides a dynamic view of the swallowing process and is frequently considered to be definitive evaluation for objective assessment of dysphagia in paediatric patients. This review focuses on the different possible aetiologies of paediatric swallowing disorders and related videofluoroscopic swallowing study procedures and appearances.

KEY WORDS: Swallowing disorders • Videofluoroscopic swallowing study • Paediatric • Dysphagia

\section{RIASSUNTO}

I disturbi della deglutizione in età pediatrica possono essere dovuti a diverse cause, dalla condizione di prematurità e patologie malformative sino al reflusso gastro-esofageo o a patologie infettive od infiammatorie del primo tratto gastroenterico. Nei neonati il processo della deglutizione è involontario e basato su meccanismi riflessi. In seguito, nell' infanzia, la fase orale diventa volontaria, mentre le fasi faringea ed esofagea rimangono involontarie. I disordini della deglutizione possono severamente compromettere le capacità respiratorie e l'apporto nutrizionale dei pazienti pediatrici. La videofluorografia è una procedura radiologica che fornisce una valutazione dinamica della deglutizione ed è generalmente considerata come la metodica strumentale definitiva per valutare in modo obiettivo la disfagia nel paziente pediatrico. Questa review mira a descrivere le differenti eziologie della disfagia in età infantile, oltre che a focalizzarsi su i rilievi videofluorografici in queste condizioni patologiche.

PAROLE CHIAVE: Disturbi della deglutizione $\bullet$ Videofluorografia $\bullet$ Pediatria $\bullet$ Disfagia

\section{Introduction}

Children are estimated to swallow 600-1,000 times a day ${ }^{1}$. Feeding and swallowing are developmental phenomena involving highly complex interactions that begin in embryologic and foetal periods and continue throughout infancy and early childhood ${ }^{23}$.

Swallowing enables saliva and bolus to be propelled from the mouth through the pharynx into the oesophagus ${ }^{4}$. When referring to swallowing, both sensory inputs (as taste, somaesthetic sensitivity, oral stereognosis, vibrotactile detection, propioception, nociception, chemical and thermal sensitivity) and motor outputs (as mastication, respiration and swallowing) are implicated ${ }^{5}$.

"Paediatric dysphagia" is not related to a specific diagnosis but refers to any disturbance of the normal swallow sequence in infants and children, as difficulties in transporting a bolus from the oral cavity to the back of the tongue or moving food into the oesophagus, compromising safety and adequacy of nutritional intake ${ }^{6-10}$.

\section{Pre- and post-natal development of swallowing mechanisms}

Through understanding of the development of feeding and swallowing skills, it is possible to shed light on how and why infants may demonstrate signs of oropharyngeal dysphagia.

During embryologic life, between the $4^{\text {th }}$ and the $7^{\text {th }}$ weeks of gestation, many processes relevant to swallowing development take place.

After the incorporation of the endoderm of the yolk sac into the embryo to form the primordial gut and rupture 
of pharyngeal membrane to form primitive choanae, separation of oesophagus and trachea from the primitive foregut is essential to avoid liquid aspiration during their passage through oesophagus ${ }^{11}$.

Thereafter, the foetal period (from the $9^{\text {th }}$ week of gestation to birth) is characterised by continuous differentiation of tissues and organs ${ }^{11}$ and by a dramatic development of swallowing, sucking and oral sensorimotor function; this latter depends from brainstem and cerebral system development and is the fundamental system for correct functioning of the former ${ }^{512}$.

Sensory cranial nerve input to the brain stem swallowing centre depends on the V, VII, IX and X cranial nerves while primary motor cranial nerve output is provided primarily by the V, VII, IX, X and XII nerves and by the cervical C1-C3 nerves ${ }^{5}$. Correct development of cranial nerves is mandatory for adequate swallowing. Myelinisation of the roots of some cranial nerves is seen during the $20^{\text {th }}-24^{\text {th }}$ weeks of gestation, and during the $35^{\text {th }}-38^{\text {th }}$ weeks the nervous system matures sufficiently to carry out integrative functions as nipple feeding ${ }^{13}$.

Moreover, other cerebral regions are implicated in sensory and motor system development such as the nucleus tractus solitarius, nucleus ambiguous, dorsal motor nucleus, hypoglossal nucleus and cerebral cortex ${ }^{14}$.

Foetal swallowing is important to regulate amniotic fluid volume and composition, as well as maturation of the foetal gastrointestinal tract and renal foetal system ${ }^{515}$. Oral motor skills also develop within a system that changes during post-natal life both in structural growth and neurological control: the successful use of the suckle reflex masters suckling and its coordination with breathing, the child's motor function (mostly involving his/her tongue) masters the stabilisation of the jaw ${ }^{1617}$.

The swallowing anatomic components of infants are different from adult ones. In the infant, the oral cavity is smaller and teeth have not erupted. We can also typically find a smoother tongue and harder palate. The larynx and hyoid bone are higher in the neck to the oral cavity, while in adults the larynx goes down to a lower area in the neck. The epiglottis is almost attached to the soft palate so that the larynx is open to the nasopharynx ${ }^{18}$.

The proper integration of the respiratory and feeding functions is mandatory because during feeding the time left for safe air exchange is reduced, minute ventilation is decreased, exhalation is prolonged and inhalation shortened. Thus, proper maturation and practice of the above functions during the first years of life enhances oral motor patterns, and this latter influences feeding performance ${ }^{16}$.

Swallowing requires both voluntary and involuntary actions and can be summed up into four phases (oral, triggering of swallowing reflex, pharyngeal and oesophageal) that involve structures and muscles of the nose, mouth, throat, chest, abdomen and digestive tract ${ }^{19}$. The oral phase consists of both preparatory and transit phases. During the preparatory phase, food and/or liquid are prepared in the oral cavity by suckling or mastications in order to form a bolus that, in the transit phase, is moved posteriorly through the oral cavity. During the pharyngeal phase, bolus is transported through the pharynx, and then through the cervical and thoracic oesophagus into the stomach during the oesophageal phase ${ }^{1120}$.

In neonates, the swallowing process is reflexive and involuntary and each of the abovementioned phases may mature at different times and/or rates. Later in infancy, the oral phase is voluntary and triggering of the swallow reflex is generally an involuntary activity, but it can be commanded voluntarily, while the pharyngeal and oesophageal phases remain involuntary ${ }^{611}$.

A child affected by chronic dysphagia will likely show delayed progression of normal feeding skills, recurrent respiratory disease and, consequently, growth deficiency. Aspiration is one of the abnormalities that may be encountered as an anomaly in the development during post-natal life and consists of passage of ingested material, refluxed contents, or oral secretions through the vocal folds into the lower respiratory tract. Recurrent or chronic aspiration is a serious risk factor in the paediatric population, resulting in infection, chronic lung disease and even death.

The physiological avoidance of aspiration depends not only on anatomical separation of respiratory and digestive tracts in embryologic life, but also on central neural processing. Fluids contacting the laryngeal mucosa evoke laryngeal chemoreflexes ${ }^{21}$ resulting in many possible responses such as rapid swallowing, apnoea, laryngeal constriction, hypertension and bradycardia, or cough; as the infant matures the formers reflexes (rapid swallowing and apnoea) become less probable, while cough and laryngeal constriction become more prominent ${ }^{22}$. However, sex-related differences have been demonstrated between early oral, tongue, pharyngeal and laryngeal motor activities: oral and upper airway skills emerge earlier in females and the latter (pharyngeal and laryngeal movements) are less rhythmic and complete in males throughout the second semester ${ }^{23}$.

\section{Paediatric swallowing disorders: aetiology}

An altered swallow sequence may compromise safety, efficiency, or adequacy of nutritional intake. Because 
swallowing and breathing share a common space in the pharynx, swallowing difficulties can have a bad effect on pulmonary health in addition to impairing nutritional intake ${ }^{24}$. Swallowing disorders occur in approximately $1 \%$ of children in the general population.

Swallowing disorders in the paediatric population are often different compared to those responsible for adult dysphagia. Many aetiologies should be kept in mind during differential diagnoses ${ }^{1125-31}$ (Table I).

\section{Clinical assessment}

Before exposing the paediatric patient to radiation during videofluoroscopic swallowing study (VFSS), accurate clinical assessment should be made by taking clinical history, evaluating sensorimotor function of the anatomical structure for swallowing and directly observing the child during a meal ${ }^{32}$.

A clinical evaluation of feeding should involve a speech language pathologist (SLP) with experience in feeding disorders during an individual session or during a clinical group session by a feeding team ${ }^{20}$.

In order to assess different potential causes of peadiatric dysphagia, the clinician has to focus on physiologicalmedical disorders, behavioural disturbances and developmental issues ${ }^{20}$.

Medical disorders may be chronic, temporary, or progressive and affect many systems related to swallowing including the respiratory, nervous and/or metabolic systems, digestive tract and craniofacial structures. Behavioural disorders must be considered as a possible contributing cause of dysphagia: the patient may adopt aggressive or unfit behaviour, refuse to be fed or have little motivation to engage in feeding-based activities. The paediatric patient may also develop inadequate skills for swallowing because of privation of correct practice for acquisition of mature skills or as a consequence of a medical or behavioural disorder. Schedule for OralMotor Assessment (SOMA) and the Dysphagia Disorder Survey are two of the more common assessment tools that the clinician can use to examine swallowing function in the paediatric population ${ }^{33}{ }^{34}$. Nevertheless, it must be said that often clinicians do not use formal assessment tools when evaluating feeding skills in children with suspected dysphagia. Several studies also highlight the inaccuracy of clinical evaluation alone in predicting airway involvement, given that silent aspiration is not uncommon in the paediatric population. When altered swallowing function is suspected in the paediatric patient, instrumental assessment should be requested to confirm the presence of dysphagia and detect aspiration risk ${ }^{11}$.

\section{Videofluoroscopic swallowing study}

VFSS is considered to be the best instrumental evaluation for objective swallowing assessment, and not just in paediatric patients ${ }^{20} 35-37$.

Table I. Different aetiologies of dysphagia.

\section{Causes of oropharyngeal dysphagia}

Neurological diseases Motor neuron disease; myopathy; birth asphyxia; cerebral palsy; microcephaly; periventricular leukomalacia

$(34.9 \%)$

Infective/flogistic pathologies Neurosyphilis; herpetic meningoencephalitis; congenital cytomegalovirus infection; dermatomyositis; epiglottitis

Structural disorders Restricted lingular frenulum; cleft lip/palate; choanal atresia or stenosis (e.g. Charge syndrome); goitre; caustic injuries

(congenital or acquired)

\section{Causes of esophageal dysphagia}

$\begin{array}{ll}\text { Motility disorders } & \text { Achalasia; scleroderma; diffuse oesophageal spasm } \\ \text { Intrinsic structural disorders } & \text { Diverticula; stenosis; oesophageal plications } \\ \text { Extrinsic structural disorders } & \text { Vertebral anomalies; foreign body: mediastinal lesions } \\ \text { Oesophagitis } & \begin{array}{l}\text { Herpes-simplex virus; Candida; gastro-oesophageal reflux disease; Crohn's disease; eosinophilic oesophagitis; caustic } \\ \text { agents }\end{array}\end{array}$

\section{Causes related to prematurity}

$(10-49 \%)$

Low gestational age at birth; low birth weight; comorbidities associated with prematurity

Cardio-respiratory diseases

Broncho-pulmonary dysplasia; laryngo-/tracheo-/bronchomalacia; cyanotic and acyanotic heart defects

latrogenic complications

Tracheostomy; feeding tube; respiratory support 
It allows concurrent visualisation of the oral, pharyngeal and oesophageal stages of swallowing ${ }^{9}$ and is essential to confirm airway protection adequacy and exclude swallowing dysfunction after clinical evaluation of feeding ${ }^{38}$.

Therefore, VFSS provides crucial diagnostic information ${ }^{39}$ and leads to a reduction in chest infections risk by detecting clinically "silent" tracheal aspiration (aspiration before, during, or after swallowing in the absence of cough or visible signs of choking) ${ }^{4041}$, especially in neurologically-based feeding disorders.

Thus, the indications for VFSS 2038 in the paediatric patient comprise:

- observation of oral preparatory, oral transit, pharyngeal and/or oesophageal phases of swallowing;

- patient hostility towards endoscopic examination;

- suspected or diagnosed anatomical anomalies of nasal cavities, oropharyngeal tract or upper oesophageal structures that are a hindrance to endoscopic evaluation;

- suspected swallowing disorder as a contributory cause of a persistent feeding refusal or a respiratory disorder;

- planning treatment to improve swallowing efficiency and reduce the risk of aspiration.

Contraindications for VFFS include:

- patients who have never fed orally;

- impossibility to adopt correct posture during the exam because of medical instability, agitation or lethargy;

- allergies to barium/iodine contrast;

- patient who cannot be transferred to the radiology department ${ }^{20}$.

Another commonly used instrumental evaluation of swallowing for paediatric patients is Fiberoptic Endoscopic Evaluation of Swallowing (FEES) 203742 , which a sensory testing of laryngeal adductor response (LAR) can be added to (Fiberoptic Endoscopic Evaluation of Swallowing and Sensory test or FEESST).

During FEES an endoscope allows observation of dynamical changes of the larynx and pharynx during the pharyngeal phase of swallowing and passage of bolus.

FEES can be performed at the bedside and repeated in a brief period and in different clinical conditions, so that it should be considered a very valuable instrumental method in follow-up ${ }^{42}$.

FEES, on the other hand, allows assessment of the pharyngeal phase only and make indirect considerations about the oesophageal and oral phases; it is only acceptable for either very young children or for older cooperating children and is not very helpful to assess repeated swallowing.
Therefore, the question about whether VFFS can be considered as the gold standard to assess swallowing disorders is still open. Studies have shown that both VFSS and FEES have comparable sensitivity, specificity and predictive abilities ${ }^{43}$, , and a valuable approach may include both examinations as complementary, when available.

\section{Practical and radiological technique}

VFSS is a fast radiographic procedure. During the exam, barium contrast agents (administered at various consistencies - from solid to liquid - according to the situation) or, if necessary, hydrosoluble no-ionic iodated agents are transported in the oro-pharyngeal cavity and oesophagus, and the sequential phases of this passage are captured in real time using fluoroscopy ${ }^{45}$.

An optimal approach to the patient can be achieved thanks to multidisciplinary management of the procedure by radiologist, radiographer and deglutologist ${ }^{45-47}$. Families have to be prepared for what to expect from the procedure, and advised that for best execution of the exam and cooperation of the children, it is advisable to bring appetising foods to be mixed with the contrast agent, familiar utensils and a seating system that children usually use during meals ${ }^{20} 37$.

Moreover, in the radiology department there should be a child-friendly environment, such as a fluoroscopy room with visual distracters (toys, boxes of rewards) and a familiar caregiver 2037 .

At present there is not a unique protocol for VFSS in infants, since the procedure is strongly influenced by individual medical conditions, feeding modality, preferred food consistencies, age and size of the paediatric patient 203738 .

Regarding the question of lack of a unique VFSS protocol, in 2013 the International Dysphagia Diet Standardisation Initiative (IDDSI) ${ }^{48}$ was founded to develop globally standardised terminology to refer to thickened liquids and texture modified foods used for patients of all ages affected by dysphagia.

During a consensus meeting, a first group of descriptors of texture and flow behaviour were developed to propose a framework to $>3,100$ people in 57 countries around the world, obtaining positive feedback. The final IDDSI framework consists of levels from 0 to 7 including both liquids and foods on a continuum and every level is identified by a number, colour codes and a text label. Level 1 (slightly thick liquids) has particular utility for paediatric patients, even if it cannot be always available in all healthcare.

However, during VFSS barium sulphate powder is usu- 
ally mixed with different textures of liquid, semi-solid and solid food (as cookies or crackers) and administered to the patient. As some authors suggest ${ }^{49}$, one-half cup of thin barium can be mixed either with $1 \frac{1}{2}$ teaspoons of thickener to obtain a nectar consistency or with $1 \frac{1}{2}$ tablespoons thickener to create a honey-like texture.

Density of barium sulfate suspension is often expressed in a weight/weight $(\mathrm{w} / \mathrm{w})$ ratio, which indicates the number of grams of active ingredient per $100 \mathrm{~g}$ of product; otherwise, it is expressed in a weight/volume $(\mathrm{w} / \mathrm{v}) \mathrm{ra}-$ tio which expresses the number of grams of active ingredient per $100 \mathrm{~mL}$ of product ${ }^{49}$. Varibar thin liquid (40\% w/v, after reconstitution; E-Z-EM Inc., Westbury, NY) and E-Z-HD (98\% w/w; E-Z-EM Inc., Westbury, $\mathrm{NY}$ ) are barium sulphate suspensions commonly used for VFSS.

Even though nectar and honey-like consistencies can be created using thickener, several barium sulfate suspensions are commercially available such as $\operatorname{Varibar}^{\circledR}$ Thin Liquid, Varibar ${ }^{\circledR}$ Nectar, Varibar ${ }^{\circledR}$ Honey, Varibar ${ }^{\circledR}$ Pudding ${ }^{49}$. For infants $\left(0-1\right.$ year), some authors ${ }^{38}$ state that the examination should start with liquids, as this texture often results to be the prevailing one in an infants' diet, and disparate type of nipples with different flows can be used ${ }^{150}$.

In patients older than 1 year, it is possible to previously evaluate their food and drink preferences ${ }^{1}$. However, the use of the patient's favourite food mixed with barium may facilitate cooperation to accept other types of food, resulting in a wider range of information. Finally, after having started the study, the radiologist and the SLP may change the volume and viscosity of the barium texture on the basis of patient's symptoms and signs detected ${ }^{37}$. The patient should not chew gum or eat for several hours prior to VFSS ${ }^{51}$ and if the child cannot autonomously feed because of a gastrostomy or nasogastric tube (NG tube), it is recommended ${ }^{37}$ to take small tastes of the foods for 1-2 weeks prior to the VFSS. When a NG tube is in place, its removal is not necessary in most cases, as swallowing evaluation can be performed anyway ${ }^{52}$ and having the tube repassed is a traumatic manoeuvre for the paediatric patient ${ }^{37}$.

Cleft lip and/or palate patients require adequate feeding methods during the VFSS. A special need feeder is a oneway valve bottle designed for infants who have sucking difficulties: it is activated by compression movements alone, so the cleft lip and/or palate patient can overcome the obstacle of sucking dysfunction during feeding ${ }^{1}$.

During VFSS, the presence of a family member who feeds the paediatric patient should be recommended, especially in infants, using child preferred utensils, like the baby's own feeding bottle, thus contributing to make the patient seat in a friendly feeding position to achieve the optimal conditions for VFSS ${ }^{20}$.

During the procedure, patient positioning depends on his/her size, age and medical conditions ${ }^{38}$. Babies, infants and children up to 3 years should be seated in usual position in their own wheelchair or a preformed seat with secure straps mounted on the X-ray equipment. When the child size exceeds preformed seat dimensions, as the fluoroscopy table is vertically positioned, the patient can sit on a step set on the lower side of the table ${ }^{3751}$.

The child has to be primarily positioned in the lateral view to assess oro-pharyngeal cavity, larynx and cervical oesophageal region. The radiologist activates the fluoroscope for few seconds prior to the administration of barium contrast-impregnated food or liquid and keeps it on as long as the bolus reaches the cervical region of oesophagus ${ }^{45}$. During the oral phase, the radiologist must assess bolus containment before the swallow (Fig. 1), the rhythmicity of jaw movements and coordination of tongue movements.

The lips, nasal cavity, cervical spine column and pharyngo-oesophageal segments are, respectively, in the anterior, superior, posterior and inferior limits of the field of view ${ }^{5354}$.

The Antero-Posterior (A-P) view is not always routinely obtained by clinicians, since the diagnostic contribution

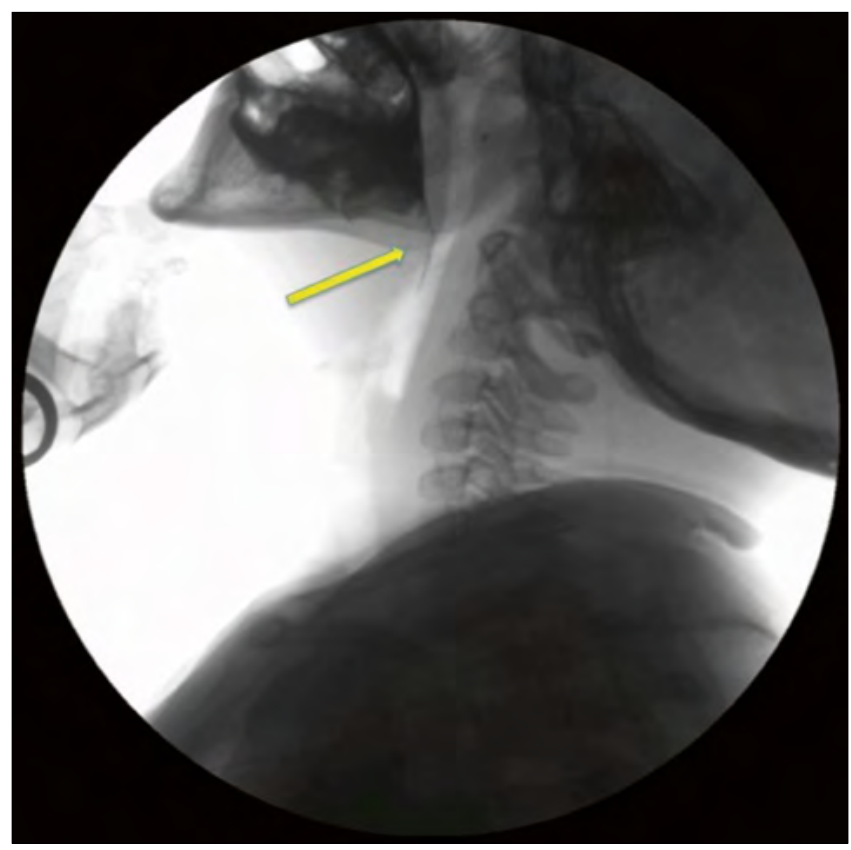

Fig. 1. Videofluorography lateral view in a 10-year-old patient. During the oral phase, a leakage of barium in the oesophagus (arrow) indicates inadequacy of bolus containment. 


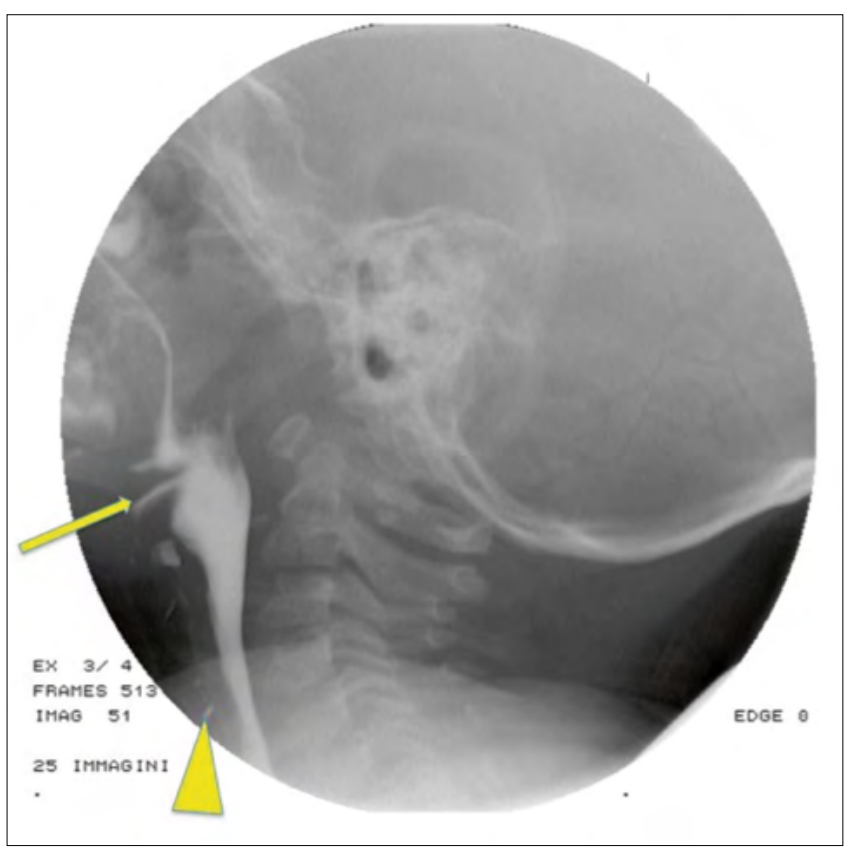

Fig. 2. Videofluorography lateral view in an 8-year-old patient with Down syndrome. During the pharyngeal phase subepiglottic penetration (arrow) and aspiration are demonstrated with persistence of contrast media in the trachea (arrowhead), in the absence of coughing.

made by an A-P view essentially concerns assessment of structural and functional symmetry and detection of unilateral abnormalities of the pharyngeal wall, as is the case with pharyngeal paresis or paralysis ${ }^{45}$.

Milliampere $(\mathrm{mA})$ and kilovolt $(\mathrm{kV})$ settings are typically dependent on the patient's age, height and weight. For a 6-month-old to 5-year-old child, the usual $\mathrm{mA}$ and $\mathrm{kV}$ settings are 58-60 $\mathrm{kVp}$ with 1-1.1 mA, while for a 10 -year-old patient these are $62 \mathrm{kVp}$ and $1.5 \mathrm{~mA}^{37}$. As several authors state, using a pulse rate of 30 pulses $/ \mathrm{sec}$ is essential to detect rapid aspiration and to recognise any bolus flow event related to the oropharyngeal phase of swallowing 45556 (Fig. 2).

\section{Interpreting results}

During VFSS, assessment of swallowing consists in observing the orally preparatory, oral transit, pharyngeal and oesophageal phases ${ }^{2037}$. Bolus formed during orally preparatory phase is held inside the oral cavity and does not move into the open larynx thanks to the base of the tongue and soft palate which close the oral cavity posteriorly 2057 .

During the oral transit phase, an anterior-to-posterior elevation of tongue push the bolus posteriorly toward the pharynx, so that pharyngeal reflex is triggered. Larynx closes by contraction of the aryepiglottic folds.
The pharyngeal phase takes place in less than a second and begins when bolus passes through the anterior faucial arch and reaches the posterior pharyngeal wall; bolus is then pushed toward the cricopharyngeal sphincter by contraction of pharyngeal constrictor muscles. Spill of bolus into the nasopharynx is prevented by elevation of the soft palate and larynx closes true and false vocal cords and aryepiglottic folds to block the way to trachea. As the oesophageal phase begins, the cricopharyngeal muscle relaxes and bolus moves through cervical and thoracic oesophagus and into the stomach thanks to oesophageal peristalsis ${ }^{57}$.

Deterioration in swallowing function can be demonstrated by several abnormalities such as delay in the initiation of the swallowing reflex, residue of contrastimpregnated food and liquid, epiglottal undercoating, penetration and aspiration ${ }^{37}$.

The presence of aspiration is characterised by the entry of ingested material below the level of the true vocal folds into the trachea ${ }^{58}$ and if aspiration occurs, the material can enter the airway before, during and/or after the pharyngeal swallow ${ }^{53}$. When the bolus blocks the patency of the airways a chocking event occurs, exposing infants to a life-threatening condition.

Penetration is present when bolus material enters the laryngeal vestibule down to the level of the true vocal folds, but it does not cross the vocal folds ${ }^{11}$ (Fig. 3).

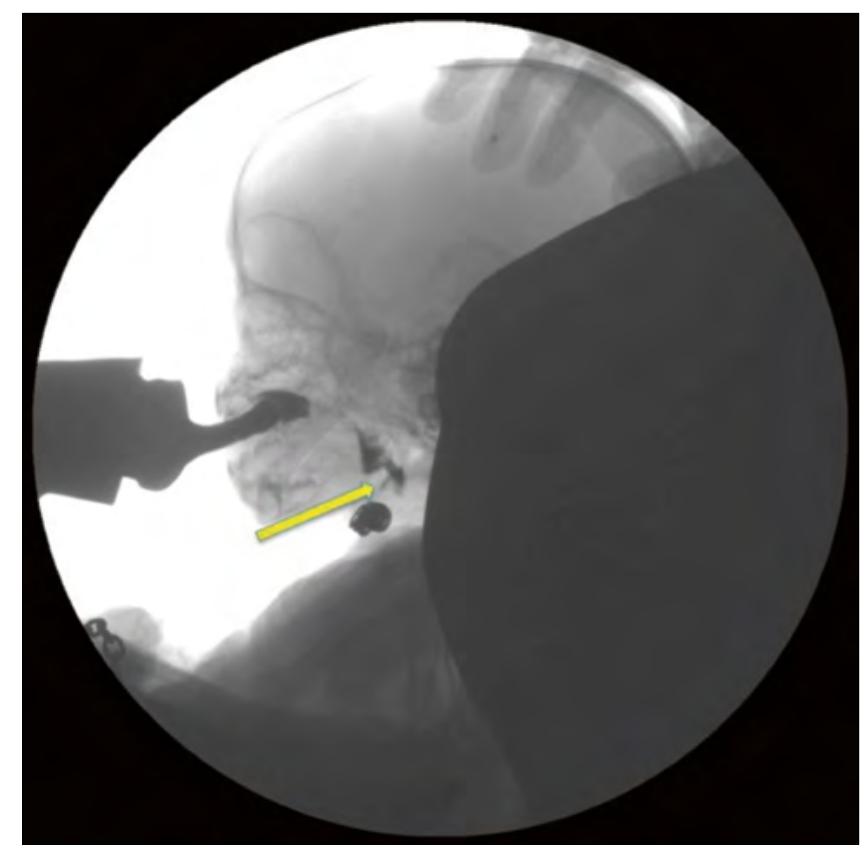

Fig. 3. Videofluorography lateral view in a 6-month-old patient with perinatal stroke shows transient sub-epiglottic penetration (arrow), in the absence of coughing. 
The Penetration-Aspiration Scale ${ }^{59}$ is a widely employed interval scale for a reliable quantification of penetration and aspiration events observed during VFSS.

The final 8-point version of the scale is multidimensional since several types of behaviours are evaluated.

Contrast-material not entering the airway is scored 1, while penetration can be scored from 2 to 5 . Score 2 is given if contrast material remains above the vocal folds but no residue is visible, while score 3 is given if visible residue remains. If contrast material contacts the vocal folds but is ejected from the airway penetration this is scored 4, while if there is no ejection of material and residue is visible, penetration is scored 5 .

Aspiration is a more severe event than penetration: it can be scored from 6 to 8 according to whether aspirated material is partially or totally expelled from the airway (score 6), subglottic residue is visible despite the patient's effort (score 7) or aspiration occurs without the patient's attempt to expel contrast material (score 8).

Another abnormality seen on VFSS is epiglottic undercoating which occurs when material penetrates underneath the epiglottis above the laryngeal vestibule ${ }^{37}$.

Deteriorated swallowing can be also displayed by a swallow reflex delayed more than $1 \mathrm{sec}^{37}$.

On VFSS some patients show a normal swallowing process in the first few swallows but, as feeding progresses, abnormalities appear. On the other hand, certain patients may have greater difficulty during first few swallows and, as they become more organised, improve their function with additional swallows. Thus, during the procedure, multiple swallows have always to be examined ${ }^{60}$. If during basic examination no symptoms appear, provocative manoeuvres can be used to evoke swallowing abnormalities, always with caution, such as body position change, always keeping in mind the patient's individual history. Protective and therapeutic manoeuvres, such as modifications regarding neck or body position, are available to prevent aspiration and limit considerable risks deriving from a sudden inability to breathe ${ }^{37}$.

VFSS must be rapidly aborted when severe aspiration occurs, oxygen level saturation drops, or if the child does not respond to protective or therapeutic manoeuvres ${ }^{3751}$. The procedure should end after having achieved all the goals of the study, trying to minimize the radiation exposure with the maximum level of clinical and radiological results 4561 .

\section{Radioprotection issues}

Videofluoroscopic analysis of swallowing is considered to be the best instrumental evaluation to objec- tively assess swallowing function after clinical feeding, confirming airway protection adequacy during the event ${ }^{20}$. However, there are limitations to the procedure such as cost, time constraints and, mostly, radiation exposure.

Although the radiation dose from VFSS is relatively low, between 0.2 and $0.85 \mathrm{mSv}{ }^{62-66}$ (for a chest $\mathrm{x}$-ray acquired in P-A the patient receives a radiation dose of $0.02 \mathrm{mSv}$ ) ${ }^{67}$ any radiation from medical tests must be minimised to comply with the "As Low As Reasonably Achievable" principle ${ }^{68}$. This is particularly true in the paediatric population. Long-term effects of radiation are increasingly acknowledged, particularly in infants, since adverse effects of radiation exposure are known to be age-dependent: children are more sensitive to radiationinduced cancer than adults and the radiogenic risk of developing a radiation-related cancer is 2-3 times higher for a young child compared with an adult exposed to an identical radiation dose ${ }^{69-71}$. Therefore, optimisation of the procedure is important to reduce the dose using registration or fluoroscopy with low exposure data, if possible, due to intrinsic high contrast differences between barium and soft tissue. Also, specific age, weight protocols and diagnostic reference levels should be set within each department for the different ages of patients ${ }^{72-76}$. In order to maintain a low dose, the radiologist should make the timing of the fluoroscopy coincide with the oral and pharyngeal phases of swallowing. In VFSS, fluoroscopy time has been shown to be highly correlated with kerma area product (KAP) values and is known as a practical tool for monitoring patient radiation dose ${ }^{77}$. Guidelines have been adopted to limit radiation exposure times, but multiple variables may influence the duration of the exam. In particular, factors influencing radiation exposure time in VFSS include medical diagnosis category, swallowing impairment severity, the clinician's experience and use of a standardised protocol.

\section{Conclusions}

Feeding and swallowing disorders present in different manners and the underlying aetiology may be difficult to determine. An evaluation of clinical history and physical examination may screen some abnormalities, but often do not provide help in identifying the underlying cause of feeding and swallowing disorders. VFSS is considered to be the best instrumental evaluation for complete assessment from the oral to pharyngeal and oesophageal phases. In addition, the procedure strongly contributes to reducing the risk of chest infections by detecting clinically "silent" tracheal aspiration. 
However, behavioural, structural and physiological disorders often coexist, complicating diagnosis and management.

For this reason, a multidisciplinary approach to diagnosis and management is helpful.

\section{Conflict of interest statement}

None declared.

\section{References}

1 Gower RE. Swallowing evaluations with the pediatric population: a comparison to standard adult protocols. Research papers 2014. Paper 512. 2014. http://opensiuc.lib.siu.edu/gs_rp/512.

2 Stevenson RD, Allaire JH. The development of normal feeding and swallowing. Pediatr Clin North Am 1991;38:1439-53. https://doi. org/10.1016/s0031-3955(16)38229-3.

3 Kahane JC. Postnatal development and aging of the human larynx. Semin Speech Lang 1983; 4:189-203.

4 Zhu M, Yu B, Yang W, et al. Evaluation of normal swallowing functions by using dynamic high-density surface electromyography maps. Biomed Eng Online 2017;16:133. https://doi. org/10.1186/s12938-017-0424-x.

5 Miller AJ. The neuroscientific principles of swallowing and dysphagia. San Diego: Singular Publishing Group; 1999. pp. 100-1.

6 Chantal L. Development of suck and swallow mechanisms in infants. Ann Nutr Metab 2015;66:7-14. https://doi. org/10.1159/000381361.

7 Arvedson JC. Feeding with craniofacial anomalies. In: Arvedson JC, Brodsky LB, editors. Pediatric swallowing and feeding: assessment and management. Second edition. Albany, NY: Singular Publishing Group; 2002. pp. 527-61.

8 Groher ME, Crary MA. Dysphagia: clinical management in adults and children. Second edition. Maryland Heights, MO: Mosby/Elsevier; 2010.

9 Miller CK, Willging JP. Advances in the evaluation and management of pediatric dysphagia. Curr Opin Otolaryngol Head Neck Surg 2003;11:442-6.

10 Dodrill P, Gosa MM. Pediatric dysphagia: physiology, assessment, and management. Ann Nutr Metab 2015;66(Suppl 5):24-31. https://doi.org/10.1159/000381372.

11 Moore KL, Persaud TVN, Torchia MG. The developing human: clinically oriented embryology. Tenth edition. Philadelphia: Elsevier; 2003.

12 Kinney HC, Brody BA, Kloman AS, et al. Sequence of CNS myelination in human infancy. II. Patterns of myelination in autopsied infants. J Neuropathol Exp Neurol 1988;47:217-34. https://doi. org/10.1097/00005072-198805000-00003.

13 Miller JL, Sonies BC, Macedonia C. Emergence of oropharyngeal, laryngeal, and swallowing activity in the developing fetal upper aerodigestive tract: an ultrasound evaluation. Early Hum Dev 2003;71:61-87. https://doi.org/10.1016/s0378-3782(02)00110-x.

14 Broussaud DL, Altschuler SM. Central integration of swallow and airway-protective reflexes. Am J Med 2000;108(Suppl 4a):62S7S. https://doi.org/10.1016/s0002-9343(99)00340-x.

15 Ross MG, Nijland MJM. Development of ingestive behaviour. Am J Physiol 1998;274:879-93. https://doi.org/10.1152/ ajpregu.1998.274.4.R879.
16 Kelly BN, Huckabee ML, Jones RD, et al. The first year of human life: coordinating respiration and nutritive swallowing. Dysphagia 2007;22:37-43. https://doi.org/10.1007/s00455-006-9038-3.

17 Morris SE, Klein MD. Pre-feeding skills: a comprehensive resource for mealtime development. Second edition. Tucson, AZ: Therapy Skill Builders; 2000.

18 Matsuo K, Palmer JB. Anatomy and physiology of feeding and swallowing - normal and abnormal. Phys Med Rehabil Clin N Am 2008;19:691-707. https://doi.org/10.1016/j.pmr.2008.06.001.

19 Sheppard JJ. Using motor learning approaches for treating swallowing and feeding disorders: a review. Lang Speech Hear Serv Sch 2008;39:227-36. https://doi.org/10.1044/0161-1461(2008/022).

20 American Speech-Language-Hearing Association. Pediatric Dysphagia. www.asha.org/Practice-Portal/Clinical-Topics/PediatricDysphagia.

21 Thach BT. Maturation and transformation of reflexes that protect the laryngeal airway from liquid aspiration from fetal to adult life. Am J Med 2001;111(Suppl 8a):69S-77S. https://doi.org/10.1016/ s0002-9343(01)00860-9.

22 Thach BT. Maturation of cough and other reflexes that protect the fetal and neonatal airway. Pulm Pharmacol Ther 2007;20:365-70. https://doi.org/10.1016/j.pupt.2006.11.011.

23 Miller JL, Macedonia C, Sonies BC. Sex differences in prenatal oral-motor function and development. Dev Med Child Neurol 2006;48:465-70.

24 Tutor JD, Srinivasan S, Gosa MM, et al. Pulmonary function in infants with swallowing dysfunction. PLoS One 2015;10:e0123125. https://doi.org/10.1371/journal.pone.0123125.

25 Bhattacharyya N. The prevalence of pediatric voice and swallowing problems in the United States. Laryngoscope 2015;125:74650. https://doi.org/10.1002/lary.24931.

26 Lefton-Greif MA, Arvedson JC. Pediatric feeding and swallowing disorders: state of health, population trends, and application of the international classification of functioning, disability, and health. Semin Speech Lang 2007;28:161-5. https://doi. org/10.1055/s-2007-984722

27 Scerrino G, Tudisca C, Bonventre S, et al. Swallowing disorders after thyroidectomy: what we know and where we are. A systematic review. Int J Surg 2017;41(Suppl 1):S94-S102. https://doi. org/10.1016/j.ijsu.2017.03.078

28 Scerrino G, Inviati A, Di Giovanni S, et al. Esophageal motility changes after thyroidectomy; possible associations with postoperative voice and swallowing disorders: preliminary results. Otolaryngol Head Neck Surg 2013;148:926-32. https://doi. org/10.1177/0194599813482299.

29 Mezoff EA. Focus on diagnosis. Pediatr Rev 2012;33:518-20. https://doi.org/10.1542/pir.33-11-518.

30 Manikam R, Perman JA. Pediatric feeding disorders. J Clin Gastroenterol 2000;30:34-46. https://doi.org/10.1097/00004836200001000-00007.

31 Buchholz DW. Dysphagia associated with neurological disorders. Acta Otorhinolaryngol Belg 1994;48:143-55.

32 Rugiu MG. Role of videofluoroscopy in evaluation of neurologic dysphagia. Acta Otorhinolaryngol Ital 2007;27:306-16.

33 Ko MJ, Kang MJ, Ko KJ, et al. Clinical usefulness of schedule for oral-motor assessment (SOMA) in children with dysphagia. Ann Rehabil Med 2011;35:477-84. https://doi.org/10.5535/ arm.2011.35.4.477.

34 Sheppard JJ, Hochman R, Baer C. The dysphagia disorder survey: validation of an assessment for swallowing and feeding function in developmental disability. Res Dev Disabil 2014;35:929-42. https://doi.org/10.1016/j.ridd.2014.02.017. 
35 Russo S, Lo Re G, Galia M, et al. Videofluorography swallow study of patients with systemic sclerosis. Radiol Med 2009;114:948-59. https://doi.org/10.1007/s11547-009-0416-4.

36 Lo Re G, Galia M, La Grutta L, et al. Digital cineradiographic study of swallowing in patients with amyotrophic lateral sclerosis. Radiol Med 2007;112:1173-87. https://doi.org/10.1007/s11547007-0214-9.

37 Hiorns MP, Ryan MM. Current practice in paediatric videofluoroscopy. Pediatr Radiol 2006;36:911-9. https://doi.org/10.1007/ s00247-006-0124-3.

38 Arvedson JC, Lefton-Greif MA. Pediatric videofluoroscopic swallow studies: a professional manual with caregiver guidelines. San Antonio: Communication Skill Builders/Psychological Corporation; 1998.

39 Reilly S, Douglas J, Oates J. Evidence based practice in speech pathology. London: Whurr Publishers; 2004.

40 Logemann JA. Evaluation and treatment of swallowing disorders. Second edition. San Diego: College-Hill Press; 1983.

41 Smith Hammond CA, Goldstein LB. Cough and aspiration of food and liquids due to oral-pharyngeal dysphagia: ACCP evidence-based clinical practice guidelines. Chest 2006;129 (Suppl 1):154S-68S. https://doi.org/10.1378/chest.129.1_suppl.154S.

42 Farneti D, Genovese E. Endoscopic criteria in assessing severity of swallowing disorders. In: Speyer R, Bogaardt H, editors. Seminars in Dysphagia. IntechOpen, September 2nd 2015. https://doi. org/10.5772/60836. Available from: https://www.intechopen.com/ books/seminars-in-dysphagia/endoscopic-criteria-in-assessingseverity-of-swallowing-disorders.

43 Gomes GF, Rao N, Brady S, et al. Gold-Standard? Analysis of the videofluoroscopic and fiberoptic endoscopic swallow examinations. J Applied Res 2003;3:89-96.

$44 \mathrm{Wu} \mathrm{CH}$, Hsiao TY, Chen JC, et al. Evaluation of swallowing safety with fiberoptic endoscope: comparison with videofluoroscopic technique. Laryngoscope 1997;107:396-401. https://doi. org/10.1097/00005537-199703000-00023.

45 Martin-Harris B, Jones B. The videofluorographic swallowing study. Phys Med Rehabil Clin N Am 2008;19:769-85. https://doi. org/10.1016/j.pmr.2008.06.004.

46 Knechtges PM, Carlos RC. The evolving role of radiologists within the health care system. J Am Coll Radiol 2007;4:626-35. https:// doi.org/10.1016/j.jacr.2007.05.014.

47 Lo Re G, De Luca R, Muscarneri F, et al. Relationship between anxiety level and radiological investigation. Comparison among different diagnostic imaging exams in a prospective single-center study. Radiol Med 2016;121:763-8. https://doi.org/10.1007/ s11547-016-0664-z.

48 Cichero JAY, Lam P, Steele CM, et al. Development of International terminology and definitions for texture-modified foods and thickened fluids used in dysphagia management: the IDDSI framework. Dysphagia 2017;32:293-314. https://doi.org/10.1007/ s00455-016-9758-y.

49 Callahan MJ, Talmadge JM, MacDougall RD, et al. Selecting appropriate gastroenteric contrast media for diagnostic fluoroscopic imaging in infants and children: a practical approach. Pediatr Radiol 2017;47:372-81. https://doi.org/10.1007/s00247016-3709-5.

50 Lefton-Greif MA, McGrattan KE, Carson KA, et al. First steps towards development of an instrument for the reproducible quantification of oropharyngeal swallow physiology in bottle-fed children. Dysphagia 2018;33:76-82. https://doi.org/10.1007/s00455017-9834-y.

51 The American College of Radiology. ACR practice parameter for the performance of the modified barium swallow. 2014. www.acr. org/ /media/7d306289d61341dd9146466186a77dbe.pdf.

52 Leder SB, Suiter DM. Effect of nasogastric tubes on incidence of aspiration. Arch Phys Med Rehabil 2008;89:648-51. https://doi. org/10.1016/j.apmr.2007.09.038.

53 Martin-Harris B, Logemann JA, McMahon S, et al. Clinical utility of the modified barium swallow. Dysphagia 2000;15:136-41. https://doi.org/10.1007/s004550010015.

54 Dodds WJ, Stewart ET, Logemann JA. Physiology and radiology of the normal oral and pharyngeal phases of swallowing. AJR Am J Roentgenol 1990;154:953-63. https://doi.org/10.2214/ ajr.154.5.2108569.

55 Mercado-Deane MG, Burton EM, Harlow SA, et al. Swallowing dysfunction in infants less than 1 year of age. Pediatr Radiol 2001;31:423-28. https://doi.org/10.1007/s002470100456.

56 Jones B, Donner MW. Interpreting the study. In: Jones B, Donner MW, editors.. Normal and abnormal swallowing: imaging in diagnosis and therapy. New York, NY: Springer Verlag; 1991. pp. 51-75.

57 Logemann JA. Manual for the videofluorographic study of swallowing. Second edition. Austin, TX: Pro-Ed Inc; 1993.

58 Robbins J, Coyle J, Rosenbek J, et al. Differentiation of normal and abnormal airway protection during swallowing using the penetration-aspiration scale. Dysphagia 1999;14:228-32. https://doi. org/10.1007/PL00009610.

59 Rosenbek JC, Robbins JA, Roecker EB, et al. A penetration-aspiration scale. Dysphagia 1996;11:93-8.

60 Newman LA, Keckley C, Petersen MC, et al. Swallowing function and medical diagnoses in infants suspected of dysphagia. Pediatrics 2001;108:E106. https://doi.org/10.1542/peds.108.6.e106.

61 O’Donoghue S, Bagnall A. Videofluoroscopic evaluation in the assessment of swallowing disorders in paediatric and adult populations. Folia Phoniatr Logop 1999;51:158-71. https://doi. org/10.1159/000021494.

62 Moro L, Cazzani C. Dynamic swallowing study and radiation dose to patients. Radiol Med 2006;111:123-9.

63 Wright RE, Boyd CS, Workman A. Radiation doses to patients during pharyngeal videofluoroscopy. Dysphagia 1998;13:113-5. https://doi.org/10.1007/PL00009554.

64 Weir KA, McMahon SM, Long G, et al. Radiation doses to children during modified barium swallow studies. Pediatr Radiol 2007;37:283-90. https://doi.org/10.1007/s00247-006-0397-6.

65 Zammit-Maempel I, Chapple CL, Leslie P. Radiation dose in videofluoroscopic swallow studies. Dysphagia 2007;22:13-5. https:// doi.org/10.1007/s00455-006-9031-x.

${ }^{66}$ Chau KH, Kung CM. Patient dose during videofluoroscopy swallowing studies in a Hong Kong public hospital. Dysphagia 2009;24:387-90. https://doi.org/10.1007/s00455-009-9214-3.

67 Huda W, Atherton JV. Energy imparted in computed tomography. Med Phys 1995;22:1263-9. https://doi.org/10.1118/1.597564.

68 United States Nuclear Regulatory Commission, Nuclear Regulatory Commission Regulations. Title 10 code of federal regulations, part 20 standards for protection against radiation. Section 20.1003 Definitions. www.nrc.gov/reading-rm/doc-collections/ cfr/part020/part020-1003.html.

69 Khong PL, Ringertz H, Donoghue V. Radiological protection in paediatric diagnostic and interventional radiology. Ann ICRP 2013;42:1-63. https://doi.org/10.1016/j.icrp.2012.10.001.

70 Alzen G, Benz-Bohm G. Radiation protection in pediatric radiology. Dtsch Arztebl Int 2011;108:407-14. https://doi.org/10.3238/ arztebl.2011.0407. 
71 Salerno S, Marrale M, Geraci C, et al. Cumulative doses analysis in young trauma patients: a single-centre experience. Radiol Med 2016;121:144-52. https://doi.org/10.1007/s11547-015-0584-3.

72 European Diagnostic Reference Levels for Paediatric Imaging (PiDRL). European Guidelines on DRLs for Paediatric Imaging. 2016. www.eurosafeimaging.org/wp/wp-content/uploads/2014/02/European-Guidelines-on-DRLs-for-Paediatric-Imaging_Revised_18-July-2016_clean.pdf.

73 Colagrande S, Origgi D, Zatelli G, et al. CT exposure in adult and paediatric patients: a review of the mechanisms of damage, relative dose and consequent possible risks. Radiol Med 2014;119:803-10. https://doi.org/10.1007/s11547-014-0393-0.

74 Salerno S, Marchese P, Magistrelli A, et al. Radiation risks knowledge in resident and fellow in paediatrics: a questionnaire survey. Ital $\mathrm{J}$ Pediatr 2015;41:21. https://doi.org/10.1186/s13052-015-0130-x.
75 Granata C, Origgi D, Palorini F, et al. Radiation dose from multidetector CT studies in children: results from the first Italian nationwide survey. Pediatr Radiol 2015;45:695-705. https://doi. org/10.1007/s00247-014-3201-z.

76 Palorini F, Origgi D, Granata C, et al. Adult exposures from MDCT including multiphase studies: first Italian nationwide survey. Eur Radiol 2014;24:469-83. https://doi.org/10.1007/s00330-0133031-7.

77 Miller DL, Balter S, Cole PE, et al. Radiation doses in interventional radiology procedures. The RAD-IR study. Part I: overall measures of dose. J Vasc Interv Radiol 2003;14:711-27. https:// doi.org/10.1097/01.rvi.0000079980.80153.4b.

Received: September 18, 2017 - Accepted: April 15, 2018

How to cite this article: Lo Re G, Vernuccio F, Di Vittorio M.L, et al. Swallowing evaluation with videofluoroscopy in the paediatric population. Acta Otorhinolaryngol Ital 2019;39:279-288. https://doi.org/10.14639/0392-100X-1942

Address for correspondence: Chiara Tudisca, Section of Radiology Di.Bi.Med., University Hospital "Paolo Giaccone", via del Vespro 127, 90127 Palermo, Italy. Tel. +39 091 238657254. Fax +39 091 9552324. E-mail: chiaratudisca@ gmail.com 